\title{
Direct-to-consumer genetic testing: An assessment of genetic counselors' knowledge and beliefs
}

\author{
Kathryn T. Hock, $M S^{1}$, Kurt D. Christensen, MPH ${ }^{2}$, Beverly M. Yashar, MS, PhD ${ }^{3,4}$, \\ J. Scott Roberts, PhD ${ }^{2}$, Sarah E. Gollust, PhD ${ }^{5}$, and Wendy R. Uhlmann, MS ${ }^{3,6}$
}

\begin{abstract}
Purpose: Direct-to-consumer genetic testing is a new means of obtaining genetic testing outside of a traditional clinical setting. This study assesses genetic counselors' experience, knowledge, and beliefs regarding direct-to-consumer genetic testing for tests that would currently be offered in genetics clinics. Methods: Members of the National Society of Genetic Counselors completed a web-administered survey in February 2008. Results: Response rate was $36 \%$; the final data analysis included 312 respondents. Eighty-three percent of respondents had two or fewer inquiries about direct-to-consumer genetic testing, and $14 \%$ had received requests for test interpretation or discussion. Respondents believed that genetic counselors have a professional obligation to be knowledgeable about direct-to-consumer genetic testing (55\%) and interpret results (48\%). Fifty-one percent of respondents thought genetic testing should be limited to a clinical setting; 56\% agreed direct-toconsumer genetic testing is acceptable if genetic counseling is provided. More than $70 \%$ of respondents would definitely or possibly consider direct-to-consumer testing for patients who (1) have concerns about genetic discrimination, (2) want anonymous testing, or (3) have geographic constraints. Conclusions: Results indicate that genetic counselors have limited patient experiences with direct-to-consumer genetic testing and are cautiously considering if and under what circumstances this approach should be used. Genet Med 2011:13(4):325-332.
\end{abstract}

Key Words: direct-to-consumer, genetic counselors, genetic testing

$\mathrm{D}$ rect-to-consumer (DTC) genetic testing is a new means of obtaining genetic testing outside of a traditional clinical setting, with companies marketing their services directly to consumers through the Internet and other media. This mode of genetic testing continues to grow, attracting attention among clinicians, scientists, professional societies, policymakers, the news media, and the public. DTC genetic testing is available for a wide array of tests, including conditions that are traditionally tested for in a clinical setting (e.g., cystic fibrosis, hereditary breast and ovarian cancer $[\mathrm{HBOC}]$ ), health-related genetic issues for which testing is not currently considered the standard of

From the ${ }^{1}$ Center for Fetal Diagnosis and Therapy, Wayne State University Physician's Group, Detroit; ${ }^{2}$ Department of Health Behavior and Health Education, University of Michigan School of Public Health, Ann Arbor; ${ }^{3}$ Department of Human Genetics and ${ }^{4}$ Department of Ophthalmology and Visual Sciences, University of Michigan, Ann Arbor, Michigan; ${ }^{5}$ Division of Health Policy and Management, University of Pennsylvania, Philadelphia, Pennsylvania; and ${ }^{6}$ Department of Internal Medicine, Division of Molecular Medicine and Genetics, University of Michigan, Ann Arbor, Michigan.

Kathryn T. Hock, MS, Center for Fetal Diagnosis and Therapy, Wayne State University Physician's Group, 3980 John R-Box 160, 4 Weber North, Detroit, MI 48201. E-mail: khock@med.wayne.edu.

Disclosure: The authors declare no conflict of interest.

Submitted for publication June 11, 2010.

Accepted for publication October 9, 2010.

Published online ahead of print January 12, 2011.

DOI: $10.1097 /$ GIM.0b013e3182011636 care (e.g., depression, pharmacogenetics, nutrigenomics, and genomic profiling), and non-health-related genetic issues (e.g., ancestry, paternity testing). The cost for DTC genetic testing ranges from less than $\$ 100$ to $\$ 3,000$ depending on the test(s) offered. $^{1-3}$ DTC genetic testing companies are growing in number. In 2002, only 14 companies offered DTC genetic testing for 7 health-related conditions. ${ }^{1}$ As of May 2010, there are more than 30 DTC genetic testing companies that offer health-related DTC genetic testing for more than 50 health-related conditions. ${ }^{4,5}$

In the DTC genetic testing approach, genetic test results are made available to consumers without a clinic visit or direct involvement of a healthcare provider. This approach of providing access to health-related genetic testing could offer potential benefits. For example, DTC genetic testing services could provide a mechanism to address the limited availability of genetic service providers across the United States. As of April 2010, there were 1,481 board certified clinical geneticists (155 of which are $\mathrm{PhD}$ medical geneticists) and 2,789 certified genetic counselors (personal communication), mainly concentrated in larger cities, with some states having only two or fewer providers. ${ }^{6}$ In addition, DTC genetic testing may be less costly to consumers or insurers, especially because a clinic visit is not involved. DTC genetic tests may also be an attractive option to consumers who are concerned about genetic discrimination and confidentiality. The advertisement of DTC tests for genetic conditions could raise public awareness and knowledge about genetic tests and empower consumers to be better advocates for their healthcare. ${ }^{7}$

DTC genetic testing also raises concerns. DTC genetic testing can be ordered without review of family and medical history information, pre- and post-test counseling, and other standard components of a traditional genetic counseling session. ${ }^{8-10}$ These standard components help ensure that the correct genetic test is ordered, and that patients understand the risks, benefits, and limitations of testing, in addition to being psychologically prepared to handle test results. Currently, a number of DTC genetic tests are being offered for genetic conditions that are not considered standard of care and do not have practice guidelines supporting their use. As DTC genetic testing does not generally involve a physician or genetic specialist, individuals who purchase DTC genetic tests are left to interpret-or misinterprettest results. ${ }^{7}$

An additional concern in offering testing DTC is that commercial interests may conflict with best clinical or public health practices. Some DTC testing companies already have a history of advertising untrue and/or exaggerated claims, particularly for conditions with complex causes. ${ }^{7,11-13}$ Companies may overemphasize the risks and severity of the conditions for which they provide testing to persuade individuals to purchase tests. ${ }^{14}$ Furthermore, the analytical and clinical validity and clinical utility of many of these tests has not yet been determined. ${ }^{15}$ It is also unknown whether all DTC genetic tests are performed in CLIA-certified laboratories. ${ }^{4}$ 
As a result of these concerns, DTC genetic testing has received increased regulatory scrutiny. Since the emergence of tests offered DTC, there has been little federal regulatory oversight over the practice of testing and state laws vary in their restrictions. ${ }^{14}$ Following Pathway Genomics' May 2010 announcement of plans to sell tests DTC at Walgreens stores, federal policymakers have taken several actions; the Food and Drug Administration sent letters to 19 companies declaring that their genetic tests are devices that require additional Food and Drug Administration scrutiny, and the US House of Representatives Committee on Energy and Commerce held public hearings. ${ }^{16}$ In addition, the Government Accountability Office investigated these tests, announcing them "misleading" and citing concern about "deceptive" marketing practices. ${ }^{17}$ As a result, a new era of regulatory attention to these types of tests and services may be emerging that may bring federal regulation in line with the many professional societies and governmental committees that have issued position statements on DTC testing within the last 6 years, including the American College of Clinical Pharmacology, ${ }^{18}$ American College of Medical Genetics, ${ }^{19,20}$ American College of Obstetrics and Gynecology, ${ }^{21}$ American Society of Human Genetics, ${ }^{10}$ Federal Trade Commission, ${ }^{22}$ Genetics and Public Policy Center, ${ }^{14}$ National Human Genome Research Institute, ${ }^{23}$ National Society of Genetic Counselors, ${ }^{24}$ and the Secretary's Advisory Committee on Genetics, Health, and Society. ${ }^{7}$

DTC genetic testing has captured the public's attention; consumers of this emerging medical service likely will be interfacing with healthcare professionals for guidance about initiating testing, understanding test results, or making healthcare decisions. $8,25,26$ Therefore, it is important to assess the role healthcare professionals will play in this new avenue for providing genetic testing services. Historically, genetic testing services have been primarily provided by clinical geneticists and genetic counselors, and over time, genetic testing for some conditions has expanded into other specialties and primary care. For this study, we decided to focus on genetic counselors, who are masters degree level trained healthcare professionals with expertise in medical genetics and counseling. Genetic counselors work in a variety of clinical settings and are frequently responsible for discussing genetic testing issues with patients and coordinating the logistics of testing. The specific aim of this study was to assess genetic counselors' experience, knowledge, and beliefs about DTC genetic testing.

\section{METHODS}

\section{Participants and procedures}

The study population consisted of genetic counselors practicing in the United States, recruited through the National Society of Genetic Counselors (NSGC) listserv. The NSGC listserv, an electronic mailing list which NSGC members can elect to subscribe to, allowed the survey to be distributed to a wide audience of genetic counselors. In February 2008, an email with a SurveyMonkey link (www.SurveyMonkey.com) was sent to an estimated 1,050 members of the NSGC listserv with an invitation to participate in an anonymous online survey about DTC genetic testing (personal communication, NSGC Executive Office). To increase the rate, a recruitment email reminder was sent 10 days after the initial invite and 1 week before closing this 1 month survey. The University of Michigan institutional review board approved the study (IRB \#16201). As an incentive, participants could separately submit their name in a drawing for one of six $\$ 50$ Amazon.com gift cards.

\section{Survey development}

The survey instrument was developed by a multidisciplinary research team from the Department of Human Genetics and the School of Public Health at the University of Michigan, representing disciplines including genetic counseling, human genetics, health policy, health psychology, and health education. A literature review was conducted to determine types of genetic tests currently offered DTC, ascertain position statements from professional and policy organizations, determine perceived risks and benefits of DTC testing, and learn about current government oversight. This information was used to develop the survey questions. An introduction was written to the survey that specifically stated that the focus of the survey was for "healthrelated DTC genetic testing that could also be offered in a clinical genetics setting." The survey instrument was piloted with two University of Michigan genetic counseling students to assess time for completion.

\section{Survey measures}

\section{Demographic and professional characteristics}

Demographic information collected included the respondent's age and regional location. Professional characteristics assessed included years of experience, whether they currently work in clinical care, and primary practice setting. Genetic counselors were also asked whether they have ever tested a patient anonymously, seen patients in genetics outreach clinics, or have provided genetic counseling by telemedicine. In addition, respondents were asked if they are a consultant or work for a DTC genetic testing company.

\section{Experience with DTC testing}

Genetic counselors' previous professional experiences with DTC genetic testing were assessed by six items. Two asked about experience with patient inquiries about DTC test services and requests for test interpretation. The other four items assessed genetic counselors' clinical and information-seeking practices regarding DTC testing (e.g., referral of patients for services, visiting DTC company websites).

\section{Knowledge about DTC testing}

Knowledge - defined as an awareness of aspects of the DTC testing process - was assessed via 20 questions across the following domains: (1) disorders for which DTC genetic testing is available (8 items); (2) the current state of regulations and oversight of DTC testing (as of the time of survey administration, in early 2008) (7 items); and (3) position statements on DTC testing from key genetics professional organizations (5 items). Items answered correctly were summed to create an overall knowledge score (out of 20 items) and domain-specific scores.

\section{Beliefs about DTC testing}

Respondents were asked about their beliefs regarding the appropriateness of offering genetic testing outside a clinical setting, whether DTC testing is acceptable when offered with genetic counseling, and perceptions about the quality of information provided about genetic testing via online materials. Perceived benefits and risks of DTC testing were assessed by asking genetic counselors to rate their level of agreement $(1=$ strongly agree to $5=$ strongly disagree) with six statements, including three risk items and three benefit items. "Strongly agree" and "agree" responses were collapsed to simplify descriptive analyses, as were "strongly disagree" and "disagree" 
responses. "Neutral" responses were retained unchanged as a response category.

\section{Professional obligations regarding DTC testing}

This section posed three items asking respondents about their perceived professional obligations regarding knowledge about DTC genetic tests, interpretation of test results, and discussion of this testing option. Respondents were also asked to indicate whether they would or would not consider referral for DTC genetic testing in three hypothetical scenarios.

\section{Open-ended questions}

Respondents were asked: "For what conditions have you ever suggested DTC genetic testing as an option for patients?" and then asked to provide "any additional comments/thoughts you may have on health-related genetic tests available direct-toconsumer."

\section{Data analysis}

Data were analyzed using standard statistical analysis via PASW Statistics for Windows, version 17.0.3. Chi-square and Mann-Whitney $U$ tests were used to assess differences in demographics between our sample population and that of the National Society of Genetic Counselors' 2008 Professional Status Survey. As only 4\% of respondents were consultants or worked for a DTC company, the decision was made by the research team to only separate out the DTC genetic counselors for the knowledge questions. For comparisons between groups (i.e., differences in knowledge scores by employment status with DTC companies), statistical significance was calculated by Welch's t-tests. Knowledge scores were created for each genetic counselor by determining the number of correct responses to the 20 knowledge items. Survey questions were removed from the analysis largely based on respondents' open-ended comments that indicated that respondents' personal interpretation of the term "DTC genetic testing company" could have affected their question interpretation and response. Important themes from genetic counselors' responses to open-ended questions provided in the survey were extracted by the lead author.

\section{RESULTS}

\section{Demographic and professional characteristics}

Three hundred and eighty-two NSGC members (36\%) completed the survey. Although comparisons could not be performed between our respondents and that of the National Society of Genetic Counselor's 2008 Professional Status Survey for age due to different response categories, data suggested that for all other demographic factors, our respondents were comparable (years of practice: $U=258,662, P=0.55$; respondent region: $\chi^{2}=6.59, P=0.25$; primary work setting: $\chi^{2}=13.60, P=$ 0.06 ). Three hundred and twelve respondents met final study eligibility by self-reporting their practice as genetic counseling in the United States and completing an informed consent item. Demographics of the final sample of 312 participants are presented in Table 1. Eighty-five percent of respondents participated in clinical care, $75 \%$ were 40 years or younger, and $42 \%$ had fewer than 5 years of experience. Seventy-two percent of respondents worked either at a university medical center or a private or public hospital, and $31 \%$ participated in outreach clinics (clinics outside the respondent's home institution). The primary areas of genetic practice most represented were prenatal $(33 \%)$, cancer $(26 \%)$, and pediatrics $(16 \%)$. Approximately $24 \%$ of respondents had tested a patient anonymously and $16 \%$
Table 1 Sample demographics

n $(\%)$

\begin{tabular}{lc}
\hline Age & \\
$20-30$ & $121(39)$ \\
$31-40$ & $113(36)$ \\
$41-50$ & $46(15)$ \\
$51-60$ & $30(10)$ \\
$>60$ & $2(1)$
\end{tabular}

Years of practice

$0-4$

$5-9$

$10-14$

$15-19$

$20-24$

$>25$

Respondent region $^{a}$

Region I

Region II

Region III

Region IV

Region V

Region VI

Primary work setting

University medical center

Private hospital/medical facility

Public hospital/medical facility

Physician's private practice

Diagnostic laboratory

Health maintenance organization

University/nonmedical center

Other

${ }^{a}$ Region I: CT, MA, ME, NH, RI, VT; Region II: DC, DE, MD, NJ, NY, PA, VA, WV; Region III: AL, FL, GA, KY, LA, MS, NC, SC, TN; Region IV: AR, IA, IL, IN, KS, MI, MN, MO, ND, NE, OH, OK, SD, WI; Region V: AZ, CO, MT, NM, TX, UT, WY; Region VI: AK, CA, HI, ID, NV, OR, WA.

of respondents had used telemedicine. Eleven genetic counselors $(4 \%)$ indicated that they currently work or serve as a consultant for a DTC genetic testing company.

\section{Experiences with DTC genetic testing}

Respondents' experiences with DTC genetic testing are summarized in Table 2. Overall, $46 \%$ of respondents had worked with patients who had initiated a discussion of DTC genetic testing; however, for the majority of these discussions $(63 \%)$, only one or two patients had raised this topic in the past 2 years. Fifteen percent or fewer of respondents had suggested DTC genetic testing as an option for a patient or received a request to 
Table 2 Experience with DTC testing

\begin{tabular}{|c|c|c|c|c|c|}
\hline \multicolumn{6}{|l|}{ Survey item } \\
\hline $\begin{array}{l}\text { Had patients ask to have their } \\
\text { DTC genetic test results } \\
\text { interpreted or discussed }\end{array}$ & $14 \%$ & & & & \\
\hline $\begin{array}{l}\text { Visited a DTC genetic testing } \\
\text { website }\end{array}$ & $75 \%$ & & & & \\
\hline $\begin{array}{l}\text { Suggested DTC genetic testing } \\
\text { as an option for a patient }\end{array}$ & $15 \%$ & & & & \\
\hline $\begin{array}{l}\text { Referred a patient to a specific } \\
\text { DTC genetic testing website }\end{array}$ & $11 \%$ & & & & \\
\hline \multirow{2}{*}{$\begin{array}{l}\text { Told a patient to search online } \\
\text { for DTC genetic testing }\end{array}$} & $8 \%$ & & & & \\
\hline & 0 & $1-2$ & $3-5$ & $6-10$ & $>10$ \\
\hline $\begin{array}{l}\text { Number of times a patient has } \\
\text { raised DTC genetic testing in } \\
\text { past } 2 \text { years }\end{array}$ & $54 \%$ & $29 \%$ & $10 \%$ & $4 \%$ & $4 \%$ \\
\hline
\end{tabular}

interpret DTC genetic test results for a patient. Even fewer had referred a patient to a specific DTC genetic testing website or told a patient to search online for DTC genetic testing. The two most common situations for which DTC genetic testing referrals was suggested were paternity testing $(n=12)$ and $B R C A 1 / 2$ for HBOC genetic testing $(n=9)$.

\section{Knowledge about DTC genetic testing}

A total of 20 knowledge questions were scored (Table 3). The mean number of questions correct for all genetic counselors was 8.8 ( $\mathrm{SD}=4.2 ; 44 \%$ correct $)$. The mean number of correct responses on the 8 -item disorders knowledge subscale was 3.2 $(\mathrm{SD}=2.0 ; 40 \%$ correct $)$. The mean number of correct responses on the regulations and oversight knowledge subscale was 3.8 ( $\mathrm{SD}=1.9 ; 54 \%$ correct). The mean number of correct responses on the position statement knowledge subscale was 1.9 $(\mathrm{SD}=1.4 ; 37 \%$ correct $)$. Among all respondents, knowledge was highest on knowing that DTC genetic testing is not currently regulated by the United States government (77\% correct) and that NSGC has issued a position statement about DTC genetic testing ( $73 \%$ correct). The majority of study participants $(68 \%)$ knew that HBOC testing is available DTC, but more than $50 \%$ of respondents answered incorrectly or "I do not know" for the other queried genetic conditions, all but one of which was available DTC at the time of the survey.

Genetic counselors who worked or consulted for a DTC genetic testing company scored significantly higher on the DTC knowledge section than genetic counselors who did not, with a mean score on the overall knowledge scale of 15.7 compared with $8.6(t=9.0, P<0.001)$. Further analysis showed that they also scored higher on the disorder knowledge subscale (6.1 vs. $3.1 ; t=8.9, P<0.001)$, regulations and oversight knowledge subscale (5.5 vs. $3.7 ; t=6.7, P<0.001)$, and position statement knowledge subscale (4.0 vs. $1.8 ; t=5.5, P<0.001)$.

\section{Beliefs about DTC genetic testing}

Respondents were divided over whether genetic testing should be limited to a clinical setting. Half (51\%) of respondents agreed, 23\% were neutral, and 27\% disagreed. Of note, approximately half $(56 \%)$ of the respondents agreed that DTC genetic testing is an acceptable method of obtaining genetic
Table 3 Knowledge about DTC testing

\begin{tabular}{|c|c|c|c|}
\hline & $\begin{array}{l}\text { Yes } \\
(\%)\end{array}$ & $\begin{array}{l}\text { No } \\
(\%)\end{array}$ & $\begin{array}{c}\text { Don't know } \\
(\%)\end{array}$ \\
\hline \multicolumn{4}{|l|}{$\begin{array}{l}\text { Diseases that can be } \\
\text { tested/screened DTC }\end{array}$} \\
\hline $\begin{array}{l}\text { Hereditary breast and ovarian } \\
\text { cancer }\end{array}$ & $68^{a}$ & 12 & 20 \\
\hline Cystic fibrosis & $48^{a}$ & 9 & 43 \\
\hline Cardiovascular disease $^{b}$ & $48^{a}$ & 4 & 48 \\
\hline Hemochromatosis & $46^{a}$ & 1 & 53 \\
\hline Alzheimer disease $\mathrm{e}^{b}$ & $41^{a}$ & 5 & 54 \\
\hline Newborn screening & $40^{a}$ & 17 & 43 \\
\hline Depression $^{b}$ & $20^{a}$ & 9 & 70 \\
\hline \multirow[t]{2}{*}{ Schizophrenia $^{b}$} & 20 & $11^{a}$ & 69 \\
\hline & $\begin{array}{l}\text { True } \\
(\%)\end{array}$ & $\begin{array}{c}\text { False } \\
(\%)\end{array}$ & $\begin{array}{c}\text { Don't know } \\
(\%)\end{array}$ \\
\hline \multicolumn{4}{|l|}{ Oversight and regulation } \\
\hline $\begin{array}{l}\text { DTC genetic testing is } \\
\text { currently regulated by the } \\
\text { US government }\end{array}$ & 2 & $77^{a}$ & 21 \\
\hline $\begin{array}{l}\text { NIH has the authority to } \\
\text { regulate DTC genetic } \\
\text { testing }\end{array}$ & 0 & $58^{a}$ & 42 \\
\hline $\begin{array}{l}\text { FTC has the authority to } \\
\text { regulate DTC genetic } \\
\text { testing }\end{array}$ & $47^{a}$ & 0 & 53 \\
\hline $\begin{array}{l}\text { FDA has authority to regulate } \\
\text { DTC genetic testing }\end{array}$ & $21^{a}$ & 30 & 48 \\
\hline $\begin{array}{l}\text { All DTC genetic testing } \\
\text { companies use CLIA } \\
\text { approved laboratories }\end{array}$ & 8 & $50^{a}$ & 42 \\
\hline $\begin{array}{l}\text { Genetic testing offered DTC } \\
\text { can be purchased } \\
\text { internationally over } \\
\text { the Internet }\end{array}$ & $61^{a}$ & 4 & 36 \\
\hline $\begin{array}{l}\text { DTC genetic testing companies } \\
\text { must demonstrate } \\
\text { clinical validity and } \\
\text { utility before marketing } \\
\text { genetic tests DTC }\end{array}$ & 6 & $67^{a}$ & 27 \\
\hline
\end{tabular}

$\begin{array}{ccc}\text { True } & \text { False } & \text { Don't know } \\ (\%) & (\%) & (\%)\end{array}$

Organizations that have issued a position statement

American Board of Genetic Counseling (ABGC)

American Board of Medical Genetics (ABMG)

American College of Medical Genetics (ACMG)

American Society of Human Genetics (ASHG)

National Society of Genetic Counselors (NSGC)

$\begin{array}{ccc}7 & 34^{a} & 59 \\ 5 & 24^{a} & 71 \\ 35^{a} & 6 & 59 \\ 21^{a} & 8 & 71 \\ 73^{a} & 7 & 20\end{array}$

NIH, National Institutes of Health; FTC, Federal Trade Commission; FDA, Food and Drug Administration; CLIA, Clinical Laboratory Improvement Amendments.

${ }^{a}$ Correct response.

${ }^{b}$ Not currently standard of care to offer genetic testing for condition in a clinical setting. 
Table 4 Beliefs about DTC testing: perceived risks and benefits

\begin{tabular}{lccc}
\hline & $\begin{array}{c}\text { Agree } \\
(\%)\end{array}$ & $\begin{array}{c}\text { Neutral } \\
(\%)\end{array}$ & $\begin{array}{c}\text { Disagree } \\
(\%)\end{array}$ \\
\hline Perceived risks & 92 & 7 & 1 \\
$\quad$ Receiving misinformation & 90 & 7 & 3 \\
$\quad \begin{array}{l}\text { Gaining a false sense of security } \\
\text { from a negative test result }\end{array}$ & 61 & 32 & 7 \\
$\quad \begin{array}{l}\text { Psychosocial harm } \\
\text { Perceived benefits }\end{array}$ & & 29 & 23 \\
$\quad \begin{array}{l}\text { Raises awareness about genetics } \\
\text { Learn about genetic conditions } \\
\text { they may be at risk for }\end{array}$ & 48 & 23 & 30 \\
$\quad \begin{array}{l}\text { Stimulates individuals to } \\
\text { facilitate family discussions }\end{array}$ & 32 & 33 & 35 \\
$\quad \begin{array}{l}\text { surrounding their personal } \\
\text { health }\end{array}$ & & & \\
\hline
\end{tabular}

testing when genetic counseling is provided, whereas $31 \%$ were neutral and $13 \%$ disagreed. Twelve percent of respondents agreed that individuals can receive adequate genetic testing information through online brochures and reading materials obtained through the Internet, whereas $23 \%$ were neutral and $65 \%$ disagreed.

Respondents were more likely to agree with the statements regarding potential DTC risks than they were to agree with the statements about potential DTC benefits (Table 4). Approximately $90 \%$ of respondents agreed that receiving misinformation and gaining a false sense of security from a negative test result were risks of DTC genetic testing, and $61 \%$ agreed that psychosocial harm was a risk. In contrast, fewer than half of the respondents agreed with the statement that DTC genetic testing raises awareness $(48 \%)$ and that DTC genetic testing provides the opportunity for individuals to learn about their risk for genetic conditions $(47 \%)$.

\section{Professional obligations regarding DTC genetic testing}

Genetic counselors felt a stronger obligation to be knowledgeable about DTC genetic testing (55\% agreement) and to interpret test results (48\% agreement) than to discuss DTC genetic testing as an option for their patients (4\% agreement; Table 5). More than $70 \%$ of respondents would definitely or possibly consider referring a patient to a DTC genetic testing company if a patient was concerned about genetic discrimination or wanted to be tested anonymously. Of note, $90 \%$ of genetic counselors would consider, or possibly consider, referring a patient to a DTC genetic testing company if there were geographic constraints (Table 5).

\section{Themes from open-ended questions}

Open-ended responses provided additional insights into genetic counselors' perspectives on acceptable parameters for offering DTC genetic testing, such as the availability of a knowledgeable healthcare professional, whether genetic counseling is provided, and the process of informed consent. Other important issues respondents raised in the open-ended responses included how to define a DTC genetic testing company, the

\begin{tabular}{|c|c|c|c|}
\hline & $\begin{array}{c}\text { Agree } \\
(\%)\end{array}$ & $\begin{array}{c}\text { Neutral } \\
(\%)\end{array}$ & $\begin{array}{l}\text { Disagree } \\
(\%)\end{array}$ \\
\hline $\begin{array}{l}\text { Knowledgeable about current genetic } \\
\text { tests offered DTC }\end{array}$ & 55 & 29 & 16 \\
\hline $\begin{array}{l}\text { Interpret and discuss DTC genetic test } \\
\text { results with patients }\end{array}$ & 48 & 19 & 33 \\
\hline \multirow{2}{*}{$\begin{array}{l}\text { Discuss DTC genetic testing as an } \\
\text { option with patients }\end{array}$} & 4 & 17 & 79 \\
\hline & $\begin{array}{l}\text { Yes } \\
(\%)\end{array}$ & $\begin{array}{c}\text { Possibly } \\
(\%)\end{array}$ & $\begin{array}{l}\text { No } \\
(\%)\end{array}$ \\
\hline \multicolumn{4}{|l|}{$\begin{array}{l}\text { Would you consider referring a patient } \\
\text { to a DTC genetic testing company if a } \\
\text { patient: }\end{array}$} \\
\hline $\begin{array}{l}\text {... was concerned about genetic } \\
\text { discrimination? }\end{array}$ & 16 & 55 & 29 \\
\hline ... wanted to be tested anonymously? & 19 & 57 & 24 \\
\hline $\begin{array}{l}\text {... was not able to obtain genetic } \\
\text { services due to geographic } \\
\text { constraints? }\end{array}$ & 29 & 60 & 10 \\
\hline
\end{tabular}

impact of limited regulations, and concerns over the financial motivations of DTC genetic testing companies. For example:

"My biggest problem with DTC companies is that their bottom line (revenues) are directly tied to how many tests are sold; is there not an obvious conflict of interest here?! Tests that are not indicated and/or not particularly useful are bound to be sold to customers. This is NOT GOOD CARE!" (participant 308).

"While I can see the potential benefit of having a few well-established DTC companies that have excellent Web sites, educational modules, and staff genetic counselors, my concerns often come back to the fact that for every single 'good' DTC company, there may be 10 'bad' companies that are offering tests in an inappropriate manner." (participant 122).

Many respondents indicated the acceptability of DTC genetic testing is not a simple yes or no answer but contingent upon other factors, including patients' access to healthcare resources and the availability of genetic counseling during the DTC testing process. Examples of such concerns include:

"The need for genetic testing services in the United States currently exceeds available clinic appointment times for faceto-face counseling. DTC, when done properly, seems to be a great method for bridging this gap." (participant 198).

"This is not an absolute yes or no. It may be acceptable to offer any type of test DTC provided that it is offered in a responsible manner with appropriate access to information, resources, and support (i.e., contact with a knowledgeable healthcare professional). The way a test is offered is far more important than the type of disease testing being offered." (participant 37).

In addition, numerous respondents expressed concern over the lack of involvement genetic counselors currently have in the development of DTC genetic testing services.

"I think DTC genetic testing is going to be a reality of the future and genetics professionals must either work with companies that offer such testing in order to improve the process and protect the consumer, or risk watching their services become less and less utilized over time." (participant 338). 
"DTC genetic testing will only continue to grow as our knowledge of genetics grows. The genetics professional community needs to determine how to best work with the companies providing these services. Certainly we have some concerns and see limitations. It is our responsibility as professionals in this field to reach out to companies offering these services and offer support, advice, and resources so that we can contribute to the responsible provision of these services." (participant 112).

\section{DISCUSSION}

This is the first published study to assess genetic counselors' experiences, knowledge, and beliefs about DTC genetic testing. Our data show that, to date, genetic counselors have had limited experiences with DTC genetic testing. Knowledge about aspects of DTC genetic testing (including regulation and oversight, position statements, and tests offered) was highly variable. Although, on average, respondents were more likely to agree with the risks rather than the benefits of testing, they do see themselves as having some professional obligations with regard to DTC testing. Genetic counselors' views toward testing were nuanced, depending on patient and contextual factors including whether patients have geographic constraints and the process of testing, such as how much information companies provide to patients, availability of counseling services, and the informed consent process.

There were a significant number of "don't know" responses to the knowledge questions, with all but five questions eliciting $40 \%$ or more "don't know" responses. It is understandable that there is a lack of knowledge about oversight of DTC genetic testing since this is currently in flux and under discussion nationally. In addition, oversight issues for genetic testing have not yet been resolved even in the clinical context. As expected, given that respondents were members of the National Society of Genetic Counselors (NSGC), most respondents knew about the NSGC's position statement about DTC genetic testing. However, most respondents were unaware of position statements in related genetics professional organizations. Although there is similarity between professional organizations' position statements on DTC genetic testing, genetic counselors generally need to be aware of the position statements in the wider clinical community since they may work on multidisciplinary teams with other professionals while caring for patients considering genetic testing.

Genetic counselors' knowledge about which diseases are currently available DTC varied by condition, which may not be particularly surprising given the number of companies and different tests offered, as well as the fact that four of the diseases queried are complex conditions for which offering testing is not currently considered standard of care (e.g., Alzheimer disease, depression). Genetic counselors were most knowledgeable about the availability of DTC testing for HBOC. This may be partially attributed to greater genetic counselor awareness of this test, possibly because HBOC has been marketed more broadly by Myriad, ${ }^{27}$ whereas other conditions inquired about in this survey have not had a similar level of advertising. It is important to note that accurate interpretation of a patient's DTC genetic test results is not dependent on knowing about the topics assessed in our knowledge questions.

The fact that approximately $90 \%$ of genetic counselors agreed that risks of DTC include receiving misinformation and gaining a false sense of security from a negative test result reflects genetic counselors' concerns regarding accurate communication of test limitations and implications of test results. Communication of pertinent information and provision of ge- netic counseling that benefit patients from the "traditional" model may be lost with DTC genetic testing. ${ }^{10}$ Furthermore, DTC companies can allow consumers to choose whether or not to include genetic test results in their medical records. As a result, some consumers may not necessarily receive appropriate follow-up and management. ${ }^{28}$ In the "traditional" model, risk assessment and pre- and posttest counseling are provided to help ensure that patients understand the purpose of genetic testing, its limitations, and the implications of test results for their healthcare and relevant family members.

Genetic counselors' limited patient experiences with DTC likely reflects that DTC genetic testing services have only been available for a short time and have yet to capture the attention of a wide range of consumers. ${ }^{26}$ However, DTC genetic testing discussions will likely increase in clinical settings as DTC genetic testing companies expand in number and tests offered and as more clients use these services. ${ }^{29}$ For example, one DTC genetic testing company, launched in 2008, has already announced an accumulation of 30,000 "active" genomes to its company's database. ${ }^{30}$

The long-established, time-intensive traditional model of offering genetic testing services has been limited to a clinical setting. DTC genetic testing challenges this model. Such challenges are not unique to genetics: HIV home testing kits and home pregnancy tests, for example, also emerged on the consumer market with questions about their validity and reliability, as well as concerns about proper oversight. ${ }^{31,32}$ Our results indicate that genetic counselors may be open to the option of DTC genetic testing, given that (1) half of respondents were neutral or disagreed with the statement that genetic testing should be limited to a clinical setting and (2) approximately half of genetic counselors did agree that offering genetic testing DTC is an acceptable method of obtaining genetic testing when genetic counseling is provided by the company. However, given that specific types of genetic tests were not defined in the survey, these results must be taken with some caution, as explained more below in the section on "Limitations".

With the increasing number of genetic tests and their incorporation into healthcare, innovative approaches to patient care and transition to population level application need to be developed. Already, genetic healthcare professionals are assessing whether videos, computer programs, CD-ROMS, and telemedicine can be used as viable resources in providing genetic information to patients. ${ }^{33-39}$ Written patient educational materials and group genetic counseling sessions have been explored in particular in prenatal genetic settings. ${ }^{33,40,41}$ Thus, a diversity of approaches are now being offered to convey genetic information in healthcare, expanding upon the more traditional model. DTC genetic testing is another approach to providing genetic testing that demands additional research and evaluation to understand its impact on patients and providers alike.

Historically, genetic healthcare professionals have served as the "gatekeepers" of genetic testing. The availability of genetic testing DTC circumvents the traditional model of offering genetic testing services. Although position statements have been put forth by multiple genetics professional committees and governmental advisory boards, the genetics community has not yet directly addressed the circumstances, types of tests, and the requirements needed for DTC genetic testing to potentially be considered as an option for providing genetic testing services. Given the variability in both the types of tests available from different companies and ways companies offer genetic testing services, it is important to not treat DTC genetic testing as a monolithic entity in evaluating this type of service delivery. 


\section{Limitations}

To date, no published studies exist regarding genetic counselors' beliefs and knowledge toward DTC genetic testing; thus, many survey questions used in this study were not validated and may not cover all important components of those constructs. Respondents were informed that the focus of all survey questions pertained to health-related DTC genetic testing that could also be offered in a clinical genetics setting. However, there is the chance that respondents thought questions pertained to all genetic testing currently offered DTC (i.e., paternity testing) and not just health-related DTC genetic testing. Another limitation of the study is that no definition was given for a DTC genetic testing company. This is problematic, given the heterogeneity among DTC genetic testing companies in terms of availability of genetic counseling services, educational information provided, and tests offered. To address this limitation, survey questions were removed from data analysis where respondent feedback indicated confusion about what was being asked and if knowing what was meant by the term "DTC genetic testing company" could have affected their interpretation and responses. Similarly, some items may have been interpreted by respondents in different ways. For example, the potential risk of receiving misinformation could be interpreted as a statement about the limited predictive power of many susceptibility tests offered by DTC genetic testing companies, a statement about the analytic validity of a test conducted at a laboratory that was not CLIA-certified, or interpreted as a lack of informed consent and the fact that results may be provided in the absence of genetic counseling. Finally, the response rate of this survey was relatively low. However, the demographic data suggest the respondents were a representative sample of genetic counselors and the response rate was within the range expected for surveys of other healthcare professionals. ${ }^{42,43}$

\section{Future directions}

Future research should focus on how other healthcare professionals view DTC genetic testing including clinical geneticists, specialists, and primary care physicians and other healthcare professionals who order genetic testing. It would be important to assess how the type of genetic test offered DTC and services provided by the company (e.g., genetic counseling, educational resources) affect views about DTC genetic testing. Other important issues to evaluate among genetic healthcare professionals, given their expertise in genetic testing, are whether DTC genetic testing should be considered as an option for offering genetic testing, what types of tests may or may not be acceptable, patient circumstances where this approach would be considered and the information and genetic counseling services that would need to be provided by the company. These are high priority issues given the expansion in number of DTC genetic testing companies, the availability of more genetic tests, the limited number of clinical genetics professionals, and the increase in media attention and public interest in DTC genetic testing.

\section{ACKNOWLEDGMENTS}

This work was supported by the University of Michigan's Rackham Graduate Student Research Grant and the University of Michigan's Department of Human Genetics. Dr. Scott Roberts and Wendy R. Uhlmann, MS, CGC, are supported by the National Institutes of Health Grant R01 HG-02213.

\section{REFERENCES}

1. Gollust SE, Wilfond BS, Hull SC. Direct-to-consumer sales of genetic services on the Internet. Genet Med 2003;5:332-337.

2. Hunter DJ, Khoury MJ, Drazen JM. Letting the genome out of the bottlewill we get our wish? N Engl J Med 2008;358:105-107.

3. Offit K. Genomic profiles for disease risk: predictive or premature? JAMA 2008;299:1353-1355.

4. Hogarth S, Javitt G, Melzer D. The current landscape for direct-to-consumer genetic testing: legal, ethical, and policy issues. Annu Rev Genomics Hum Genet 2008;9:161-182.

5. Genetics and Public Policy Center. Updated chart of direct-to-consumer genetic testing companies available. Available at: http://www.dnapolicy.com/ news.release.php?action $=$ detail\&pressrelease_id $=137$. Updated March 9, 2010. Accessed March 30, 2010.

6. American Board of Medical Genetics. Number of certified specialists in genetics. Available at: http://www.abmg.org/pages/resources_certspecial.shtml. Updated. Accessed April 17, 2010.

7. Secretary's Advisory Committee on Genetics, Health and Society. A roadmap for the integration of genetics and genomics into health and society. Washington, DC: Department of Health \& Human Services; 2004.

8. Goddard KAB, Duquette D, Zlot A, et al. Public awareness and use of direct-to-consumer genetic tests: results from 3 state population-based surveys, 2006. Am J Public Health 2009;99:442-445.

9. Borry P, Howard H, Sénécal K, Avard D. Health-related direct-to-consumer genetic testing: a review of companies' policies with regard to genetic testing in minors. Fam Cancer 2010;9:51-59.

10. Hudson K, Javitt G, Burke W, Byers P. ASHG statement on direct-toconsumer genetic testing in the United States. Am J Hum Genet 2007;81: $635-637$.

11. Geransar R, Einsiedel E. Evaluating online direct-to-consumer marketing of genetic tests: informed choices or buyers beware? Genet Test 2008;12:1323.

12. Matloff E, Caplan A. Direct to confusion: lessons learned from marketing BRCA testing. Am J Bioeth 2008;8:5-8.

13. Wasson K. Consumer alert: ethical issues raised by the sale of genetic tests directly to consumers. Am J Bioeth 2008;8:16-18.

14. Genetics and Public Policy Center. Direct-to-consumer genetic testing: empowering or endangering the public? Available at: http://www.dnapolicy.org/ policy.issue.php?action=detail\&issuebrief_id=32. Updated May 30, 2008. Accessed August 2, 2010.

15. McGuire AL, Burke W. An unwelcome side effect of direct-to-consumer personal genome testing: raiding the medical commons. JAMA 2008;300: 2669-2671.

16. Stein R. Genetic testing mix-up reignites debate over degree of federal regulation needed. Washington Post July 17, 2010;A1.

17. Kutz G. Direct-to-consumer genetic tests: misleading test results are further complicated by deceptive marketing and other questionable practices. GAO10-847T. Washington, DC: United States Government Accountability Office; 2010.

18. Ameer B, Krivoy N. Direct-to-consumer/patient advertising of genetic testing: a position statement of the American College of Clinical Pharmacology. J Clin Pharmacol 2009;49:886-888.

19. American College of Medical Genetics Board of Directors. ACMG statement on direct-to-consumer genetic testing. Genet Med 2004;6:60.

20. American College of Medical Genetics Board of Directors. ACMG statement on direct-to-consumer genetic testing. Available at: http://www.acmg.net/Static Content/StaticPages/DTC_Statement.pdf. Updated April 7, 2008. Accessed August 2, 2010.

21. Committee on Genetics, Committee on Ethics, American College of Obstetricians and Gynecologists. ACOG committee opinion No. 409: direct-toconsumer marketing of genetic testing. Obstet Gynecol 2008;111:14931494.

22. Federal Trade Commission. At-home genetic tests: a healthy dose of skepticism may be the best prescription. Available at: http://www.ftc.gov/bcp/ edu/pubs/consumer/health/hea02.shtm. Updated July 2006. Accessed August 2, 2010 .

23. National Human Genome Research Institute. Direct to consumer marketing of genetic tests. Available at: http://www.genome.gov/12010659. Updated March 18, 2010. Accessed May 8, 2010.

24. National Society of Genetic Counseling. Position statements. Available at: http://www.nsgc.org/about/position.cfm. Updated 2007. Accessed March 30,2010 .

25. McGuire AL, Diaz CM, Wang T, Hilsenbeck SG. Social networkers' attitudes toward direct-to-consumer personal genome testing. Am J Bioeth 2009;9:3-10.

26. Kolor K, Liu T, St. Pierre J, Khoury MJ. Health care provider and consumer awareness, perceptions, and use of direct-to-consumer personal genomic tests, United States, 2008. Genet Med 2009;11:595.

27. Myers MF, Chang MH, Jorgensen CP, et al. Genetic testing for susceptibility to breast and ovarian cancer: evaluating the impact of a direct-to-consumer 
marketing campaign on physicians' knowledge and practices. Genet Med 2006;8:361-370

28. Wasson K, Cook ED, Helzlsouer K. Direct-to-consumer online genetic testing and the four principles: an analysis of the ethical issues. Ethics Med 2006;22:83-91.

29. Wade $\mathrm{CH}$, Wilfond BS. Ethical and clinical practice considerations for genetic counselors related to direct-to-consumer marketing of genetic tests. Am J Med Genet C Semin Med Genet 2006;142C:284-292.

30. Dolan B. TEDMED: 23andMe has 30,000 "active" genomes, launching "Relative Finder" soon. Available at: http://mobihealthnews.com $/ 5131$ / 23 andme-has-30000-active-genomes-launching-relative-finder-soon/. Updated October 28, 2009. Accessed March 30, 2010.

31. Wright AA, Katz IT. Home testing for HIV. N Engl J Med 2006;354:437440 .

32. Hicks JM. Home testing: to do or not to do? Clin Chem 1993;39:7-8.

33. Clayton EW, Hannig VL, Pfotenhauer JP, Parker RA, Campbell PW 3rd, Phillips JA 3rd. Teaching about cystic fibrosis carrier screening by using written and video information. Am J Hum Genet 1995;57:171-181.

34. Green MJ, Peterson SK, Baker MW, et al. Effect of a computer-based decision aid on knowledge, perceptions, and intentions about genetic testing for breast cancer susceptibility: a randomized controlled trial. JAMA 2004; 292:442-452.

35. Cull A, Miller H, Porterfield T, et al. The use of videotaped information in cancer genetic counselling: a randomized evaluation study. $\mathrm{Br} \mathrm{J}$ Cancer $1998 ; 77: 830-837$.
36. Dabney MK, Huelsman K. Counseling by computer: breast cancer risk and genetic testing. Genet Test 2000;4:43-44.

37. Wang C, Gonzalez R, Milliron KJ, Strecher VJ, Merajver SD. Genetic counseling for BRCA1/2: a randomized controlled trial of two strategies to facilitate the education and counseling process. Am J Med Genet A 2005; 134A:66-73.

38. Abrams D, Geier M. A comparison of patient satisfaction with telehealth and on-site consultations: a pilot study for prenatal genetic counseling. J Genet Couns 2006;15:199-205.

39. Zilliacus E, Meier B, Lobb E, Kirk J, Warwick L, Tucker K. Women's experience of telehealth cancer genetic counseling. J Genet Couns 2010;19: $463-472$.

40. Skinner CS, Schildkraut JM, Berry D, et al. Pre-counseling education materials for BRCA testing: does tailoring make a difference? Genet Test 2002;6:93-105.

41. Calzone KA, Prindiville SA, Jourkiv O, et al. Randomized comparison of group versus individual genetic education and counseling for familial breast and/or ovarian cancer. J Clin Oncol 2005;23:3455-3464.

42. Braithwaite D, Emery J, de Lusignan S, Sutton S. Using the Internet to conduct surveys of health professionals: a valid alternative? Fam Pract 2003;20:545-551.

43. Dobrow MJ, Orchard MC, Golden B, et al. Response audit of an Internet survey of health care providers and administrators: implications for determination of response rates. $J$ Med Internet Res 2008;10:e30. 